\title{
Review
}

Yahaya Yakubu, Norashidah Mohamed Nor* and Emilia Zainal Abidin

\section{A systematic review of micro correlates of maternal mortality}

https://doi.org/10.1515/reveh-2017-0050

Received December 27, 2017; accepted April 12, 2018; previously published online May 5, 2018

Abstract: In the year 2000, the World Health Organization launched the Millennium Development Goals (MDGs) which were to be achieved in 2015. Though most of the goals were not achieved, a follow-up post 2015 development agenda, the Sustainable Development Goals (SDGs) was launched in 2015, which are to be achieved by 2030 . Maternal mortality reduction is a focal goal in both the MDGs and SDGs. Achieving the maternal mortality target in the SDGs requires multiple approaches, particularly in developing countries with high maternal mortality. Lowincome developing countries rely to a great extent on macro determinants such as public health expenditure, which are spent mostly on curative health and health facilities, to improve population health. To complement the macro determinants, this study employs the systematic review technique to reveal significant micro correlates of maternal mortality. The study searched MEDLINE, PubMed, Cumulative Index to Nursing and Allied Health Literature (CINAHL), Science Direct, and Global Index Medicus of the World Health Organization. Our search was time framed from the 1st January, 2000 to the 30th September, 2016. In the overall search result, 6758 articles were identified, out of which 33 were found to be eligible for the review. The outcome of the systematic search for relevant literature revealed a concentration of literature on the micro factors and maternal mortality in developing countries. This shows that maternal mortality and micro factors are a major issue in developing countries. The studies

\footnotetext{
*Corresponding author: Norashidah Mohamed Nor, Department of Economics, Faculty of Economics and Management, University Putra Malaysia, Selangor, Malaysia, E-mail: norashidah@upm.edu.my Yahaya Yakubu: Department of Economics, Faculty of Economics and Management, University Putra Malaysia, Selangor, Malaysia; and Department of Economics, Faculty of Social and Management Sciences, Bauchi State University Gadau, Bauchi State, Nigeria Emilia Zainal Abidin: Department of Environmental and Occupational Health, Faculty of Medicine and Health Sciences, University Putra Malaysia, Selangor, Malaysia
}

reviewed support the significant relationship between the micro factors and maternal mortality. This study therefore suggests that more effort should be channelled to improving the micro factors in developing countries to pave the way for the timely achievement of the SDGs' maternal mortality ratio (MMR) target.

Keywords: maternal mortality; micro factors; SDGs; systematic review.

\section{Introduction}

The inception of the Millennium Development Goals (MDGs) in 2000 sought to reduce the maternal mortality ratio (MMR) by 75\% between 1990 and 2015 as one of its many goals. In 2015, the developing and the developed regions of the world only reduced the MMR by $44 \%$ (from 385 to 216$), 44 \%$ (430-239) and 57\% (23-12) respectively. Out of the 303,000 global maternal deaths in 2015, 99\% occurred in developing countries, with sub-Saharan Africa and Southern Asia contributing $67 \%$ and $22 \%$ of the deaths in the developing regions respectively [1]. Though numerous studies have been conducted on the causes of maternal mortality, the scourge however seems unabated, particularly in developing countries. This could be a result of the reliance on macro factors such as public health expenditure. It has been shown that developing countries excessively allocate public health expenditure to curative care by purchasing tertiary health facilities [2]. However, studies have revealed that, though macro factors have some impact on health, they could not be the only determinants of population health, and $[3,4]$ found the impact of public spending on population health to be tenuous and statistically insignificant, hence, the need for a complementary approach.

With the completion of MDGs, unachieved MMR targets in the MDGs and the inception of the Sustainable Development Goals (SDGs) in 2015 with more ambitious goals, there is need for a multidimensional approach if the SDGs' MMR target should not end being unachieved. One of the focal goals of the SDGs is to reduce the MMR to at least 70 per 100,000 live births by 2030 . The inability to achieve the 
MDGs' MMR target strengthen the need for a multidimensional approach to achieving the SDGs target. A shift from the business as usual approach, where efforts to improve health are concentrated on curative and medical facilities to a more innovative and multiple approaches in which the community is carried along is suggested [5]. Hence, identifying different factors that have more effect on maternal mortality is required to inform the allocation of resources towards achieving the SDGs' maternal mortality target [6]. A possible complementary approach to reducing maternal mortality is to focus on micro factors at individual, household and community levels, such as education, age at marriage, parity/fertility level, access to improved water and sanitation. Numerous studies on the effect of these micro factors exists, yet these factors are neglected, which is probably responsible for the unabated MMR particularly in developing regions. According to [5, 7], the poor health condition of African countries results from the neglect of these micro factors. The micro factors are often referred to as the social determinants of health (SDH).

SDH are defined by $[5,8]$ as the conditions within which individuals are born, live, grow, work and age. These conditions could be cultural, environmental and communities and individual's attitudes and behaviours. Broadly, SDH is used to describe non-medical factors such as education, beliefs or behaviours and attitudes of the people that have far reaching effects on population health [9]. There is a suggestion that population health can only be achieved when SDH are addressed, and that the SDH are beyond the health sector and its policies [10]. The range of views on SDH suggest that the SDH are social-, environmental-, cultural-, community- and individualbased factors. Although SDH might be common across nations, the impacts could vary depending on the nature and development of a society. This study is interested in identifying important SDH across the literature and the impacts on population health such as maternal mortality. The study therefore employs the systematic review technique to identify the significant micro correlates of maternal mortality.

\section{Literature review}

In the search for literature, we explored popular online databases; MEDLINE, PubMed, Cumulative Index to Nursing and Allied Health Literature (CINAHL), Science Direct and Global Index Medicus of the World Health Organization. Our search was time framed from the 1st January, 2000 to the 30th September, 2016. We choose this time limit because this period witnessed an upsurge in studies on factors that affect maternal mortality due to the MDGs' targets. Generally, our inclusion criteria were: study must be in the English language; be a research journal article and; include at least a micro factor and its effect on maternal mortality. Review articles and commentaries were excluded. We used the Boolean search modes and searched the terms "social determinants of health", "maternal mortality", "maternal mortality rate" and "maternal mortality ratio". We filtered the results for human related study and the available full text. In the overall search result, 6758 publications (MEDLINE $=313$, CINAHL $=90, \quad$ PubMed $=1780$, Science Direct $=4085$, Global Index Medicus $=490$ ) were identified. The result of our search is presented in Figure 1. We adopted [11]'s mode of stating the results of the literature search in a systematic review, known as the PRISMA flow diagram. At the end of the selection process, 33 articles passed the inclusion criteria and were therefore synthesized.

The selection process after identification from the electronic search involved screening for duplicates. An article is likely to appear in two or more of the databases, for example, PubMed contains articles from MEDLINE, hence, the need for screening duplicates. In the next stage, we reviewed the titles and abstracts to identify potential articles that were likely to examine the effect of micro factors on maternal mortality. At the final stage, full texts were verified for review.

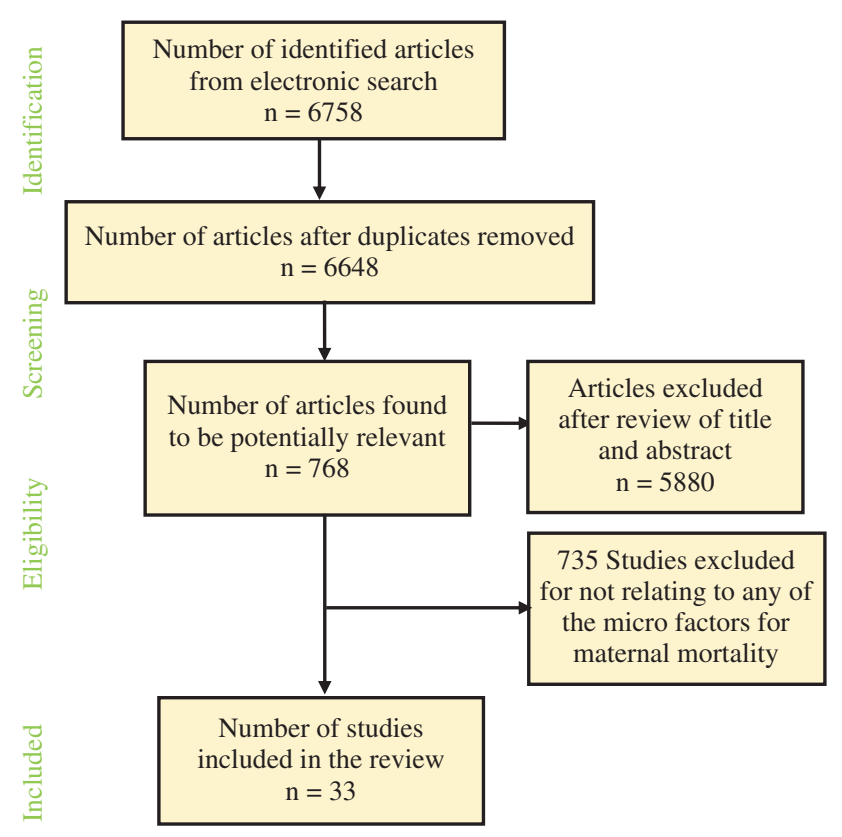

Figure 1: PRISMA diagram showing selection process of articles for micro factors and maternal mortality. 
SDH are a range of multiple factors across individuals households and communities, hence, most of the articles reviewed contain more than one SDH. We therefore reviewed articles based on a particular SDH. Thus, an article could be reviewed more than once, depending on the number of factors included in the article. Micro correlates of maternal mortality studied in the articles are education, fertility rate, parity, maternal age, wealth/poverty, status of women, access to improved sanitation and water sources and access to electricity.

\section{Education and maternal mortality}

From the reviewed literature, education appeared to be the most studied social determinant of health vis-à-vis maternal mortality. All the studies that included education, either in the form of literacy, years of schooling or completed level of education, as presented in Table 1, found the relationship between education and maternal mortality in the expected direction [12-30]. Of all the 19 studies that included the education parameter, only two were insignificant. This shows that education is influential in reducing maternal mortality. With such sweeping outcomes in the literature, education may be playing a dynamic role by influencing protective factors of maternal mortality such as prenatal and postnatal care, and institutional delivery.

Educated women are more exposed to having an informed reproductive behavior, such that they access reproductive health facilities frequently and timely. When women are educated, they increasingly improve their status, gain autonomy, awareness, responsibility and have control over their fertility and reproductive activities such as in the use of contraceptives, prenatal and postnatal care and facility delivery $[19,20]$. Similarly, educated women participate in the labor force to earn income, which could support their autonomy and medical costs, and maintain a good sanitary environment which reduces the risk of infection such as sepsis. This dimensional effect of education is probably the reason for its consistency in influencing maternal mortality. Although [17, 30]'s findings were in the expected direction, the results were insignificant. These were attributed by the authors to the narrow dispersion between literates and illiterates in South-West Ethiopia and uniformly limited access to antenatal care among women in rural Nepal.

The concentration of these studies in the low and middle income countries (LMIC) as shown in Table 1 reveals that the effect of education on maternal mortality is a serious issue in developing countries. This could be due to the low level of social and economic development in the developing regions, which includes low levels of education and literacy. As shown in Table 1, [25] not only revealed that women of Q1 (lowest), Q2 and Q3 education level have odds ratio (OR) of 5.62 (3.45-9.16), 2.51 (1.33-4.74) and $2.43(1.42-4.18)$ of maternal mortality with $\mathrm{p} \leq 0.001$, 0.01 and 0.001 , respectively, compared to women with the Q4 (highest) education level in 29 countries of Africa, Asia, Latin America and the Middle East, however, disaggregating the countries based on the human development index (HDI) further reveals education to significantly reduce the risk of maternal death only in countries with medium and low HDI. Women in the lowest quintile (Q1) of education in the low and medium HDI countries were found to have 6.31 (3.45-11.51) and 6.09 (2.50-14.88) ORs of maternal mortality with $\mathrm{p} \leq 0.001$, respectively, compared to those in the highest quintile (Q4) of education. Similarly, women in the second quintile (Q2) of education in low and middle HDI countries had 2.39 (1.07-5.35) and 3.54 (1.26-9.93) ORs of maternal mortality with $\mathrm{p} \leq 0.05$, respectively, compared to women in the highest quintile (Q4) of education. On the contrary, women with Q1 education in countries with high HDI do not only have low OR, 1.77 (0.17-18.7), but this was insignificant in reducing maternal deaths.

Also discernible from this review is the concentration of the literatures on maternal education. The relevance of male education to maternal mortality reduction should not be underestimated particularly in most of the developing countries where families are heavily patriarchal. In African society, men have absolute dominion over their wives, hence they control the women's life style, including their health seeking decision [31]. In a patriarchal setting, women's status (autonomy in decision making) does not only depends on her education and empowerment, but also on the support of the male counterpart in the union. This support and the recognition of her right to partake in decisions is positively associated with the male's education [27]. Male education is therefore expected to play role in maternal mortality [27]. The effect of both male and female literacy on maternal mortality was explored and it was found that both significantly reduce maternal mortality with male literacy being more significant, $p<0.001$ and $\mathrm{p}<0.05$, respectively.

\section{Fertility level and maternal mortality}

Fertility rate and its dynamics such as parity have been also identified in the literature to have influence on 


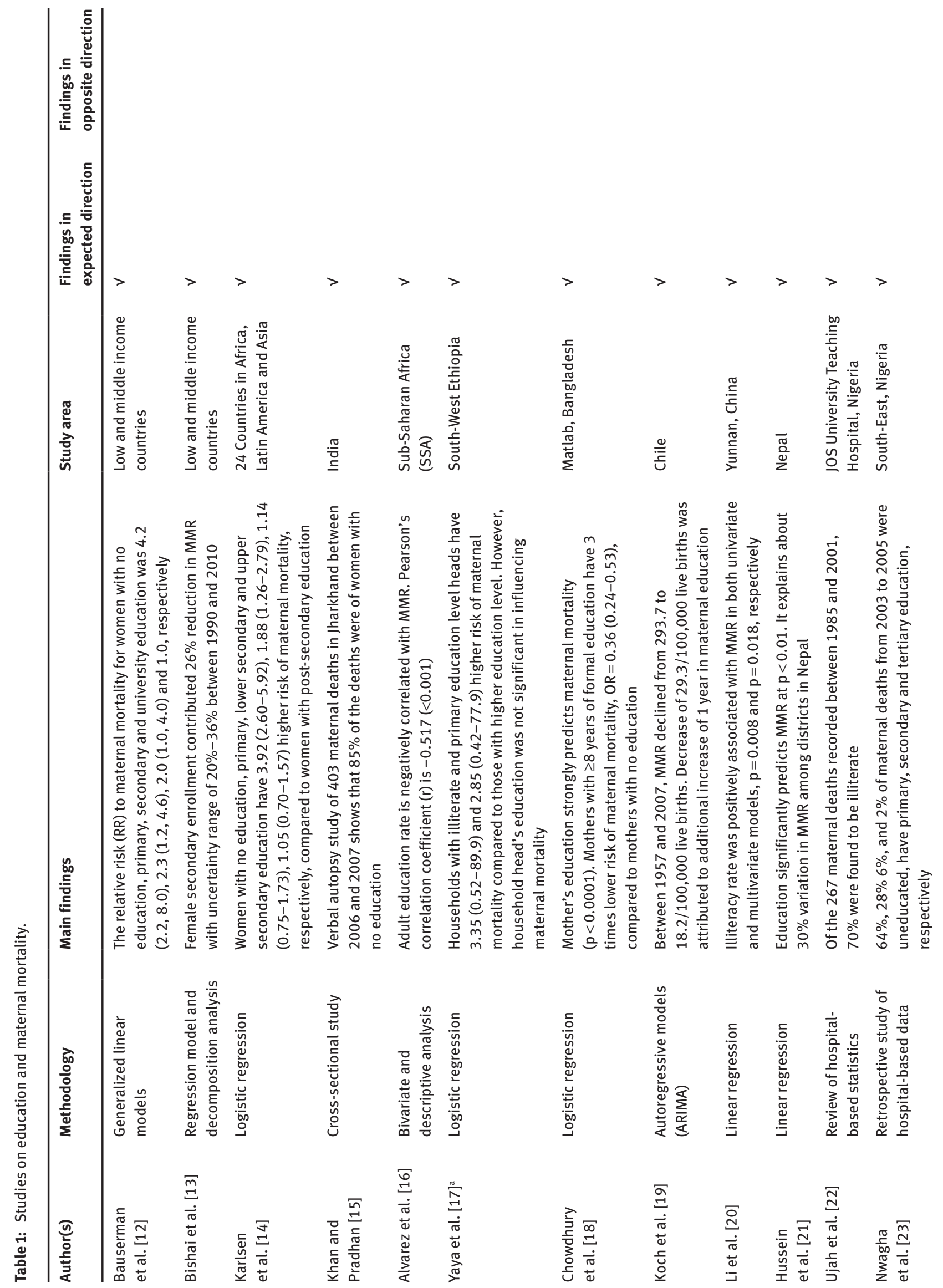




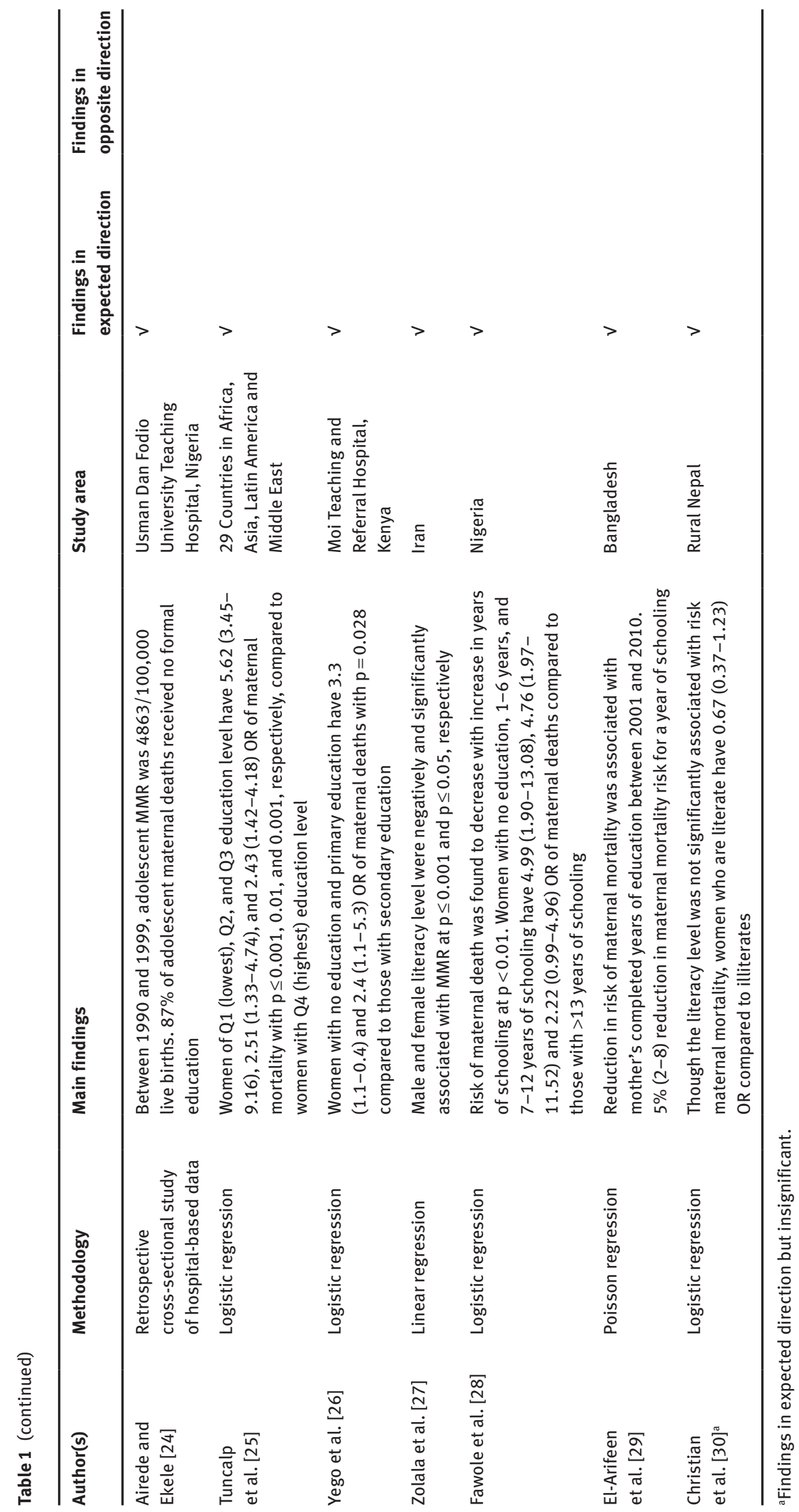


maternal mortality. This study considers parity as a component of fertility because the number of times a woman gives birth determines her fertility level. Ten of the articles included in this review, as presented in Table 2, identify the relationship between fertility rate and maternal mortality. Out of the ten articles, nine found the relationship in the expected direction [21-23, 28, 29, 32-35], while only one is in the opposite direction [30]. Women with higher fertility rate and parity are more susceptible to maternal death. The number of times a woman gives birth shows the frequency of her exposure to the risk of pregnancy complications that might lead to death, and the rate at which a woman is exposed to such risk makes her more probabilistic to maternal death.

El-Arifeeh et al. [29] found high parity of $\geq 4$ to be significantly associated with maternal death with OR of 1.8 (1.37-2.38) compared to < 4 parity in Bangladesh. Further, a decline in maternal mortality occurred between 2001 and 2010 , and the authors found $21 \%$ of the 14,310 estimated maternal deaths in 2010 was averted due to a decline in number of births. Similarly in Nigeria, [28] found multiparous mothers of $>4$ children to have 3 times higher risk of maternal mortality compared to mothers of $\leq 4$ children, at $2.91(1.30-6.52)$ OR, and a probability value of 0.01 . The synergy in support of positive relationship between fertility/ parity level and maternal mortality provided by findings in Table 2 supports the fact that the more women are exposed to reproductive activities, the higher will be the risk of maternal death. However, in the case of parity, reverse causation may arise such that women with higher parity might have lower maternal mortality rate. This perhaps occurs because only surviving women who live longer bear more children. This probably underscores the contrary finding of [30] in rural Nepal, where lower mortality rate was associated with higher parity.

Identifying multiparous mothers as being at higher risk of maternal mortality is not enough for policy implication. There is need to understand at what level the risk to a multiparous mother start. Multiparity starts from two children and above. From the articles included in this study, having parity of two children is not associated with risk of maternal mortality. Three of the articles found multiparous $\geq 5$ to be at risk [22, 23, 34], one found $\geq 3$ [35], while [28] and [29] revealed $>4$ and $\geq 4$, respectively. The rest of the studies do not have specific level of multiparity. Hence, a multiparous mother of $\geq 3$ is likely to be at risk of maternal death. However, a primipara (a woman who has only given birth once, opposite of multipara) could also be at higher risk of maternal death compared to multiparous mother of two [34]. A higher exposure to maternal mortality risk with hazard ratio of 1.18 (1.04-1.4) was revealed for mothers with one child compared to mothers with two to four children. This might have arisen from pregnancy complications such as obstructed labor resulting from becoming pregnant at younger age. Early marriage is therefore likely to compound primipara maternal mortality risk.

\section{Maternal age at birth and maternal mortality}

Maternal age at birth plays a significant role in maternal mortality due to respective vulnerability of different reproductive age brackets to pregnancy-related complications such as haemorrhage, eclampsia and puerperal sepsis. Studies on maternal age and maternal mortality identify two major age brackets of the reproductive age that correlate significantly and positively with maternal mortality, these are young maternal age (YMA) $<20$ years, and advanced maternal age (AMA) $\geq 30$ years. In the articles included in this review as shown in Table 3 [22, 29, 30, 35-37, 39-41], found that AMA is associated with increase in maternal mortality.

Though the choice of AMA differs in the separate studies, it is generally $\geq 30$ years, and as AMA increases upward, the risk of maternal mortality also increases. Study have revealed that the relative risk of maternal mortality increases with increase in maternal age [41]. The relative risk was found to be 2 times [OR $=1.63(0.69-3.86)$ ] higher in age 30-34, 7 times [OR =7.00 (3.02-16.20)] higher in age 35-39 and 30 times [OR $=30.24(11.35-80.56)$ ] higher in age $\geq 40$, compared to age 20-29. Similarly, [30] found that women of AMA of $\geq 35$ have higher maternal mortality at 0-42 days and 43-364 days after delivery, with $\mathrm{OR}=4.04$ (1.69-9.64) and 3.01 (0.98-9.27), respectively, compared to mothers of age $<35$. In a study of 29 countries across Africa, Asia, Latin America and the Middle East, [36] found AMA to significantly increase the risk of maternal death. AMA of $35-39,40-44$ and $\geq 45$ were found to have $\mathrm{OR}=1.7(1.2-2.6), 2.6(1.4-4.7)$ and $4.3(1.5-12.1)$ of maternal death, they have 2, 3 and 4 times higher risk of maternal death, respectively, compared to age 20-34.

On the other hand, YMA is also revealed by some studies to increase the likelihood of maternal mortality as shown in Table 3 [22, 24, 29, 35, 38, 40, 42], all revealed that YMA positively correlated with maternal mortality. Early marriage YMA exposes women to childbearing at an adolescent age which endangers them to pregnancy complications such as obstructed labor. Obstructed labor is found to be common among adolescent married women due to the immaturity of their pelvis, which could be due to their young age [43]. YMA generally ranges from 15 to 


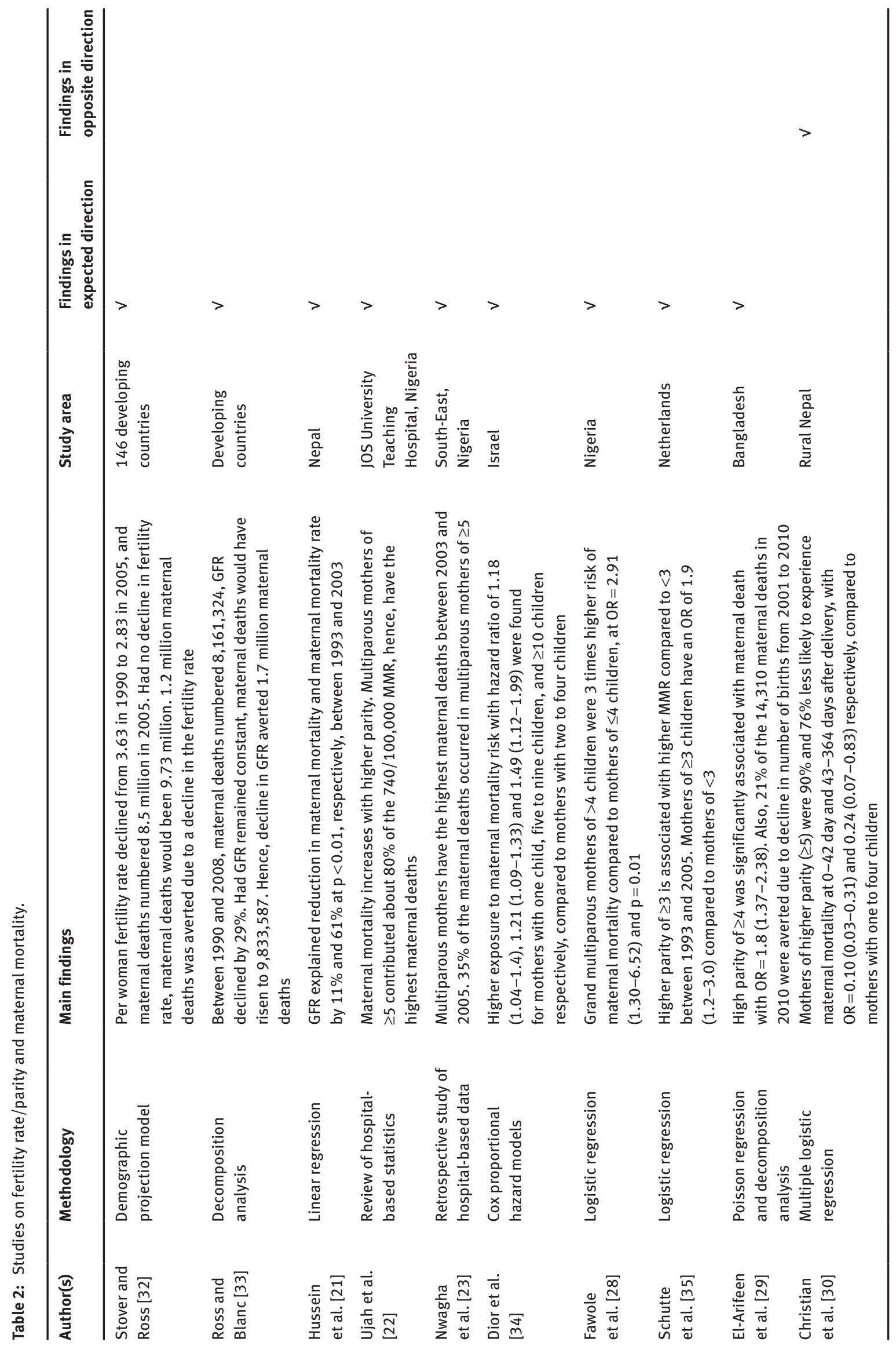




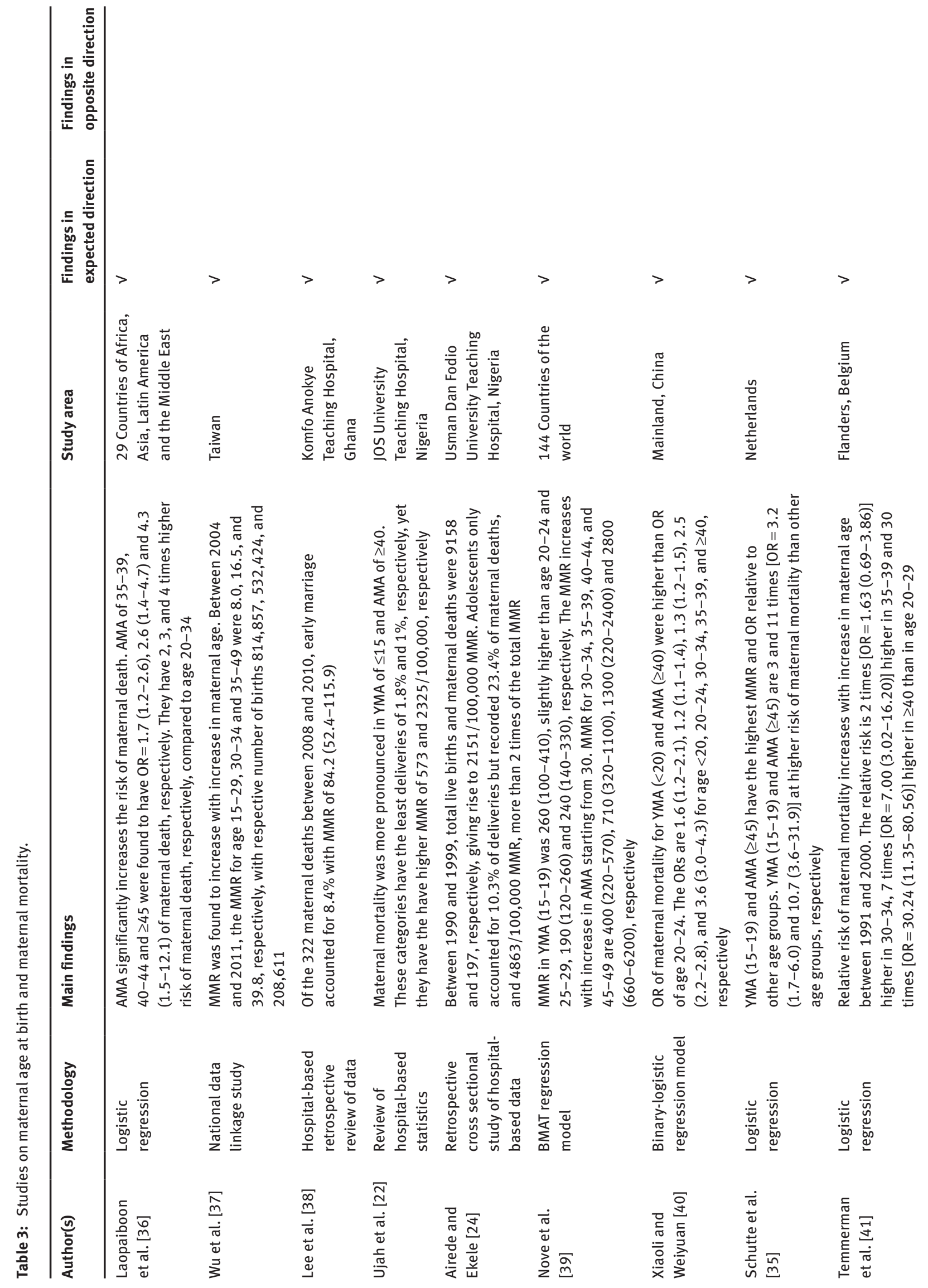


19 years, however, [22] and [24] considered age $\leq 15$ and 12-19 years, respectively. This perhaps is because the studies were conducted in the northern part of Nigeria where marriage within such an age bracket is prevalent. Study have shown that women of YMA of $<20$ years are 2 times at higher risk of maternal mortality with OR, 1.9 (1.1-2.8), compared to women of maternal age 21-30 in India [42]. In the study of [24], a teaching hospital-based study in Nigeria, adolescent mothers who accounted for only $10.3 \%$ of the total 9158 deliveries between 1990 and 1999 recorded $23.4 \%$ of the maternal deaths. This gave rise to adolescent MMR of 4863/100,000, more than twice the total MMR of 2151/100,000. Generally, from the studies in this review, age risk for maternal mortality is dichotomized into YMA and AMA, and are all significantly associated with an increase in maternal mortality.

However, it will be interesting to know at what age among the two identified ages women are at higher risk of maternal mortality. The general presumption is that adolescent are likely to have higher maternal mortality risk compared to mothers of older age, however, existing evidence appears contradictory and at times inconsistent [39]. Generally, empirical evidence suggests both to be associated with increase in maternal mortality, more evidence points to AMA playing a more significant role in increasing maternal mortality than YMA [44]. From Table 3, [35] shows that the risk of maternal mortality is higher in AMA $\geq 45$ than in YMA $<20,11$ and 3 times at higher risk than other age groups, with an OR 10.7 (3.6-31.9) and 3.2 (1.7-6.0), respectively. In mainland China, AMA $\geq 40$ and YMA $<20$ have 3.6 (3.0-4.3) and 1.6 (1.2-2.1) ORs of maternal mortality, respectively, compared to maternal age of 20-24 [40]. In Bangladesh, the risk of maternal mortality is $1.26(0.84-1.88)$ and $1.79(1.33-2.41)$ higher in pregnancy at YMA $<20$ and AMA $\geq 35$, respectively, compared to pregnancy at other ages [29]. Similarly, in a study of 144 countries of the world, [39] found that MMR of YMA (15-19) was 260 (100-410), slightly higher than age 20-24 and 25-29, 190 (120-260) and 240 (140-330), respectively. The MMR increases with an increase in AMA starting from 30 years. MMR for 30-34, 35-39, 40-44 and 45-49 were found to be 400 (220-570), 710 (320-1100), 1300 (220-2400) and 2800 (660-6200), respectively.

AMA could be more significantly associated with increase in maternal mortality due to the relationship between older ages and some direct and indirect causes of maternal mortality such as haemorrhage, placenta praevia, diabetes and hypertension. The proportion of women of older ages who died of direct causes of maternal mortality such as amniotic embolism and obstetric haemorrhage is relatively higher compared to women aged 15-29 [37]. Similarly, AMA increases the risk of gestational 
diabetes, antepartum haemorrhage, placenta praevia, hypertension, suspected intra-uterine growth restriction, operative vaginal and cesarean deliveries [45-50]. Hence, women of AMA could be said to be more at risk of maternal death compared to their counterparts at YMA.

\section{Other micro factors and maternal mortality}

Due to less number of studies that included women's status, income/poverty, access to improved water sources and sanitation and access to electricity, these factors are discussed under the heading "Other Micro Factors". Table 4 presents the main findings of the association between these factors and maternal mortality.

Women's status in the household is expected to reduce the risk of maternal mortality through their ability to influence health seeking behaviours such as prenatal and postnatal care, and fertility control through use of contraceptives. Though less studied in the literature, a few articles reviewed in this study revealed women's status to contribute to the reduction in maternal mortality. Different terms such as women's empowerment, women's position in the society, gender inequality, control of resources and female autonomy are used interchangeably in the literature as indicators of women's status [54]. Specifically, different studies referred to women's participation in decision making, particularly in the household, as an indicator of women's status; the ability to influence their environment through participation in household decision making on issues that concern them, such as health seeking and reproductive issues, household's purchases, freedom of movement particularly visits to relatives and personal resources control [55-59]. Three (3) articles in Table 4 that included women's status in this review used political and economic participation, and household decision making ability of women in society.

Bishai et al. [13] Found women's empowerment through political and economic participation to reduce maternal mortality in 146 LMIC, between 1990 and 2010. Women's participation in government and the labor force accounted for 5.5\% and $0.3 \%$ reduction in MMR, respectively, between 1990 and 2010. The contribution of labor force participation was very minimal probably due to the low level of women's education and employment in most of the LMIC. In some individual countries, these variables might play important roles, depending on the level of women's political and economic participation in a country. In Nepal, [21] revealed that women's political and economic participation explained 35\% and 36\% of the variation in the maternal mortality rate and maternal mortality ratio, respectively, among districts in Nepal. In the effect of household's decision making ability, [51] reveal inequality against women to positively correlate with high maternal mortality in Honduras. In interviews and group discussions with women in the Coastal Miskito, Honduras, women reported being prevented by spouses from seeking medical attention by withholding money or permission, which had led to some of the maternal deaths. This is probably because the society is patriarchal, where males dominate decisions in the household. Where men exercise dominance over women, which is found mostly in developing countries, women are at risk of maternal mortality due to not being able to decide or being part of decision that affects their health, particularly their reproductive health. In India, $74 \%$ of maternal mortality was associated with non-participation of women in their health decisions during pregnancy, the decisions were by the husband or his family [60].

Income or poverty level is another micro determinants identified in this review as a correlate of maternal mortality. In the articles reviewed in this study, as presented in Table 4, income or poverty is revealed to correlate negatively or positively with maternal mortality $[20,21,29,30$, 42, 51]. Li et al. [20] found income to be significantly and negatively associated with MMR in Ethiopia at $\mathrm{p}<0.01$ in a univariate model, it reduced MMR by $30 \%$. In multivariate regression, it became insignificant when adjusted for prenatal care and hospital delivery. However, it remained significant when adjusted for contraceptive use, clean drinking water and modern home delivery. This shows that income influences maternal mortality through prenatal care and hospital delivery. It also further revealed that there was probably unbearable cost attached to prenatal care and hospital delivery in Ethiopia which could have prevented the poor from utilizing maternal healthcare services. Hence, the richest and the poorest households were reported to have the lowest and the highest risk of maternal mortality, respectively, in Ethiopia. The poorest, poor, and rich categories of households had the ORs of 2.29 (0.91-6.44), 1.98 (0.77-5.59), and 1.46 (0.54-4.28), respectively, compared to the richest households [17].

Similarly in India, poverty was strongly and positively associated with risk of maternal death. Households below the poverty line were found to be 5 times at higher risk, with 5.4 (4.0-6.8) OR, compared to the non-poor [42]. However, in rural Nepal, economic status measured by land ownership, radio ownership and roof material, though insignificant in influencing maternal mortality, had the ORs of $0.70(0.48-1.02), 0.80$ (0.52-1.23), 0.80 


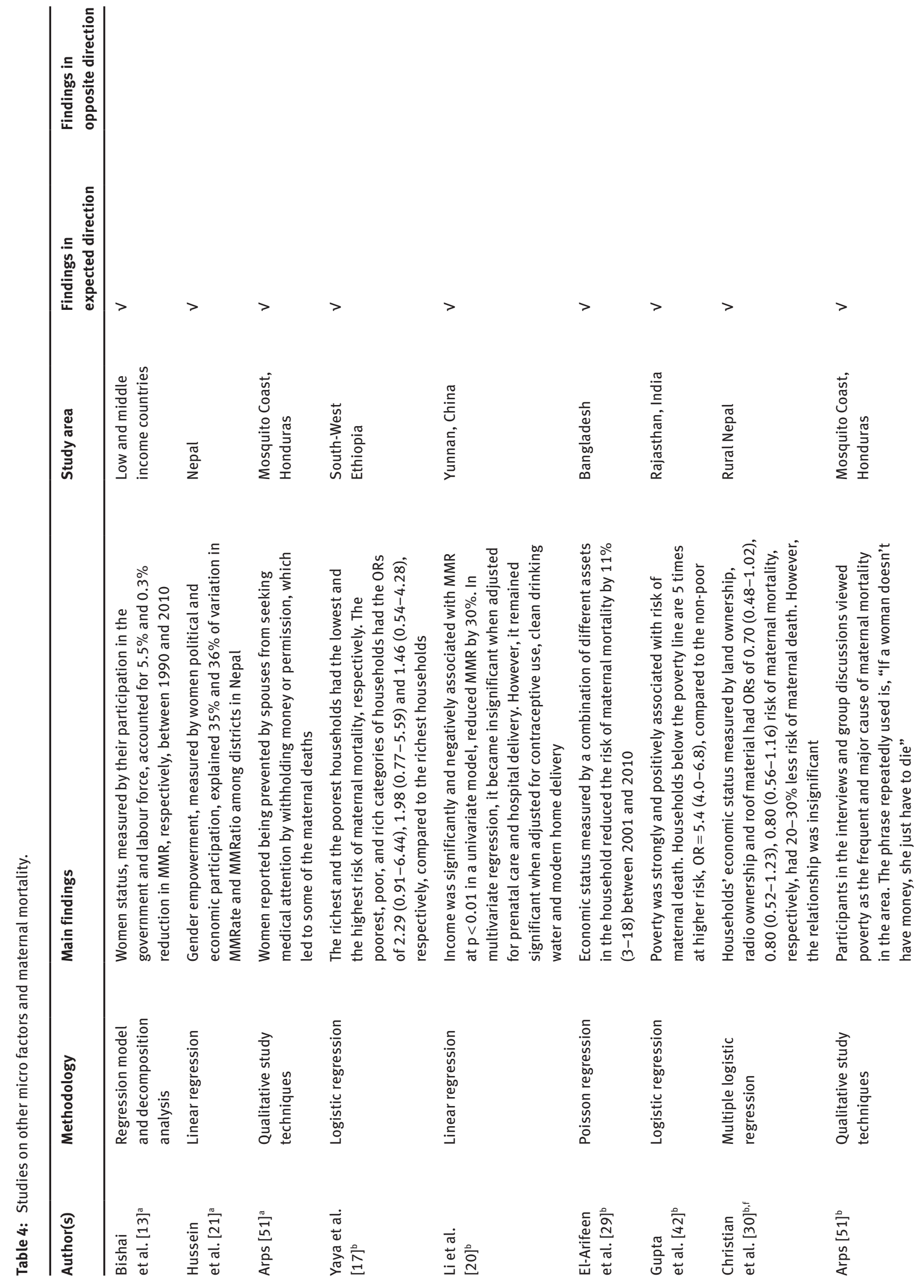


(0.56-1.16) risk of maternal mortality, respectively. Ownership of these assets make households $20-30 \%$ less likely to experience maternal death [30]. The insignificance was perhaps due to low disparity in income among the inhabitants of the study areas [30]. Generally, wealth is perceived as having a significant effect in reducing maternal mortality because of the wealthier-healthier notion [61]. Income makes nutritional foods and proper and timely healthcare accessible and affordable at the time of pregnancy, hence, maternal mortality can be reduced with higher income.

Access to electricity is also associated with maternal mortality. Though only identified in a single article among the articles reviewed, it plays important role in reducing maternal mortality [13]. It was found that rural access to electricity accounted for $13.5 \%(3 \%-24 \%)$ changes in maternal mortality ratio. Also, a study outside this review in rural Kenya [62], found access to electricity to reduce maternal mortality. Access to electricity facilitates the use of surgical equipment in medical facilities when there is pregnancy complication such as obstructed labor. Also, adequate and required cooling systems for the preservation of bagged blood is made possible with electricity. Hence, safe blood would always be available for administration in the case of haemorrhage. Most of the developing countries suffer inadequate and epileptic supply of electricity, this causes most of obstetric surgeries particularly in rural areas to be unsafe.

Access to better source of drinking water and sanitation were found to be associated with maternal mortality in the articles reviewed [16, 52, 53]. Li et al. [52] studied 193 countries and found the population with access to improved water source and sanitation to be $42 \%$ and $48 \%$ less likely to experience maternal mortality, respectively. The respective ORs were $0.58(0.39-0.86)$ and $0.52(0.32-$ 0.85 ) with p-value 0.008 and 0.009 . Similarly, [16] found access to improved water source and sanitation to negatively correlate with MMR with respective correlation coefficients (r) of -0.399 and -0.261 at $p$-value of 0.008 and 0.091, respectively, in sub-Saharan Africa. In Surabaya, Indonesia, unavailability of toilet facilities was revealed to increase the risk of maternal mortality by 3 times, OR of 9 (1.0-7.7) [53]. Poor water and sanitation facilities could lead to various infections that could aggravate maternal mortality. For example, malaria and dengue, which are water-related insect vector-borne infections, are associated with anemia during pregnancy and may lead to maternal death. Similarly, unimproved sanitation could lead to infection such as sepsis, which also aggravates maternal mortality. Globally, infections account for about $15 \%$ of pregnancy related mortality [63]. Improved water 
and sanitation are therefore necessary in reducing maternal mortality.

\section{Conclusion}

This systematic review included a final total of 33 articles, of which all, except one in the relationship between parity and maternal mortality, show the significant contribution of micro factors either in the form of education, fertility level, maternal age at birth, status of women, income/poverty, access to electricity or access to improved water sources and sanitation in reducing the risk of maternal mortality. Micro factors at individual, household and community level are therefore necessary impetus for curtailing the seemingly globally unabated maternal mortality. Paying attention to these factors by policy makers is of utmost importance, particularly with the over-ambitious SDGs in focus.

An interesting outcome of this review is the concentration of the articles in the developing countries, virtually all the studies were conducted in developing countries. This emphasises the fact that maternal mortality is a developing countries' issue $-99 \%$ of maternal mortality occurs in developing countries. Hence, the study, in addition to other different studies, gives a focal insight to the developing countries on another dimension (micro factors) of reducing maternal mortality, and on which synergies should be channelled towards, in order to timely achieve the SDGs' target of maternal mortality. This is very necessary as the macro factors such as public health expenditure are not expectedly effective in improving population health in developing countries [3, 4]. This study therefore suggest that more effort should be channelled into improving the micro factors by developing countries to pave way for the timely achievement of the SDGs' MMR target.

\section{Author Statement}

Research funding: Authors state no funding involved. Conflict of interest: Authors state no conflict of interest. Informed consent: Informed consent is not applicable. Ethical approval: The conducted research is not related to either human or animal use.

\section{References}

1. World Health Organization. Trends in maternal mortality: 1990 to 2015, estimates by WHO, UNICEF, UNFPA, World Bank Group and the United Nations Population Division. Geneva; 2015. Available from: http://www.who.int/reproductivehealth/publications/ monitoring/maternal-mortality-2015/en/
2. Filmer D, Hammer J, Pritchett L. Weak links in the chain: a diagnosis of health policy in Poor countries. World Bank Res Obs 2000;15(2):199-224.

3. Filmer D, Pritchett $L$. The impact of public spending on health: does money matter? Soc Sci Med 1999;49:1309-23.

4. Kim K, Moody PM. More resources better health? A crossnational perspective. Soc Sci Med 1992;34(8):837-42.

5. World Health Organization. Health in all policies: Report on perspectives and intersectoral actions in the African region. Brazzaville; 2013. Available from: http://apps.who.int/iris/bitstr eam/10665/127848/1/9789290232445.pdf.

6. Alkema L, Chou D, Hogan D, Zhang S, Moller A, Gemmill A, et al. Global, regional, and national levels and trends in maternal mortality between 1990 and 2015, with scenario-based projections to 2030: a systematic analysis by the United Nation Maternal Mortality Estimation Inter-Agency Group. Lancet 2015;6736(15):1-13.

7. Afolabi BM, Clement CO, Ekundayo A, Dolapo D. A hospitalbased estimate of major causes of death among under-five children from a health facility in Lagos, Southwest Nigeria: Possible indicators of health inequality. Int J Equity Health 2012;11(1):1-15.

8. World Health Organization. Rio political declaration on social determinants of health. In: World Conference on Social Determinants of Health. Rio de Janeiro: World Health Organization; 2011. p. 1-7. Available from: http://www.who.int/sdhconference/declaration/Rio_political_declaration.pdf.

9. Braveman P, Egerter S, Williams DR. The social determinants of health: Coming of age. Annu Rev Public Health 2011;32:381-98.

10. World Health Organization. World conference on social determinants of health - 2011. Geneva; 2012. Available from: http:// www.who.int/sdhconference/resources/wcsdh_report/en/.

11. Moher D, Liberati A, Tetzlaff J, Altman DG. Preferred reporting items for systematic reviews and meta-analyses: The PRISMA statement. Phys Ther 2009;89(9):873-80.

12. Bauserman M, Lokangaka A, Thorsten V, Tshefu A, Goudar SS, Esamai F, et al. Risk factors for maternal death and trends in maternal mortality in low- and middle-income countries: a prospective longitudinal cohort analysis. Reprod Health 2015;12(Suppl 2):S5.

13. Bishai DM, Cohen R, Alfonso YN, Adam T, Kuruvilla S, Schweitzer J. Factors contributing to maternal and child mortality reductions in 146 low- and middle- income countries between 1990 and 2010. PLoS One 2016;11(1):1-14.

14. Karlsen S, Say L, Souza J-P, Hogue C), Calles DL, Gülmezoglu $\mathrm{AM}$, et al. The relationship between maternal education and mortality among women giving birth in health care institutions: analysis of the cross sectional WHO global survey on maternal and perinatal health. BMC Public Health 2011;11(1):1-10.

15. Khan N, Pradhan MR. Identifying factors associated with maternal deaths in Jharkhand, India : a verbal autopsy study. J Heal Popul Nutr 2013;31(2):262-71.

16. Alvarez JL, Gil R, Hernández V, Gil A. Factors associated with maternal mortality in Sub-Saharan Africa: an ecological study. BMC Public Health 2009;8:1-9.

17. Yaya Y, Eide KT, Norheim OF, Lindtjørn B. Maternal and neonatal mortality in south-west Ethiopia: estimates and socio-economic inequality. PLoS One 2014;9(4):1-13.

18. Chowdhury ME, Botlero R, Koblinsky M, Saha SK, Dieltiens G, Ronsmans C. Determinants of reduction in maternal mortality 
in Matlab, Bangladesh: a 30-year cohort study. Lancet 2007;370(9595):1320-8.

19. Koch E, Thorp J, Bravo M, Gatica S, Romero CX, Aguilera H, et al. Women's education level, maternal health facilities, abortion legislation and maternal deaths: a natural experiment in Chile from 1957 to 2007. PLoS One 2012;7(5):e36613.

20. Li J, Luo C, Deng R, Jacoby P, De Klerk N. Maternal mortality in Yunnan, China: Recent trends and associated factors. Br J Obstet Gynaecol 2007;114(7):865-74.

21. Hussein J, Bell J, Iang MD, Mesko N, Amery J, Graham W. An appraisal of the maternal mortality decline in Nepal. PLoS One 2011;6(5):e19898.

22. Ujah IAO, Mutihir JT, Aisien OA, Glew R, Vanderjagt D, Uguru VE. Factors contributing to maternal mortality in northcentral Nigeria : a seventeen-year review. Afr J Reprod Health 2005;9(3):27-40.

23. Nwagha UI, Nwachukwu D, Dim C, Ibekwe PC, Onyebuchi A. Maternal mortality trend in south east Nigeria: less than a decade to the Millennium Developmental Goals (MDGs). J Womens Heal 2010;19(2):323-7.

24. Airede LR, Ekele BA. Adolescent maternal mortality in Sokoto, Nigeria. J Obstet Gynaecol (Lahore) 2003;23(2):163-5.

25. Tuncalp Ő, Souza J, Hindin M, Santos C, Oliveira T, Vogel J, et al. Education and severe maternal outcomes in developing countries: A multicountry cross-sectional survey. $\mathrm{Br}$ J Obstet Gynaecol 2014;121(suppl. 1):57-65.

26. Yego F, Este CD, Byles J, Williams JS, Nyongesa P. Risk factors for maternal mortality in a tertiary hospital in Kenya: a case control study. BMC Pregnancy Childbirth 2014;14:1-9.

27. Zolala F, Heidari F, Afshar N, Haghdoost AA. Exploring maternal mortality in relation to socioeconomic factors in Iran. Singapore Med J 2012;53(10):684-9.

28. Fawole A, Shah A, Fabanwo A, Adegbola O, Adewunmi A, Eniayewun $A$, et al. Predictors of maternal mortality in institutional deliveries in Nigeria. Afr Health Sci 2012;12(1):32-40.

29. El-Arifeen S, Hill K, Ahsan KZ, Jamil K, Nahar Q, Kim P. Maternal mortality in Bangladesh: a countdown to 2015 country case study. Lancet 2014;384:1366-74.

30. Christian P, Katz J, Wu L, Kimbrough-pradhan E, Khatry SK, Leclerq SC, et al. Risk factors for pregnancy-related mortality: a prospective study in rural Nepal. J R Inst Public Heal 2008;122(2):161-72.

31. Berhan Y, Berhan A. Reasons for persistently high maternal and perinatal mortalities in Ethiopia: part II-socio-economic and cultural factors. Ethiop J Health Sci 2014;24:119-37.

32. Stover J, Ross J. How increased contraceptive use has reduced maternal mortality. Matern Child Health J 2010;14(5):687-95.

33. Ross JA, Blanc AK. Why aren't there more maternal deaths? A decomposition analysis. Matern Child Health J 2012;16(2):456-63.

34. Dior UP, Hochner H, Friedlander Y, Calderon-margalit R, Jaffe D, Burger A, et al. Association between number of children and mortality of mothers: results of a 37-year follow-up study. Ann Epidemiol 2013;23(1):13-8.

35. Schutte JM, Steegers EAP, Schuitemaker NWE, Santema JG, De Boer K, Pel M, et al. Rise in maternal mortality in the Netherlands. Br J Obstet Gynaecol 2010;117(4):399-406.

36. Laopaiboon M, Lumbiganon P, Intarut N, Mori R, Ganchimeg T, Vogel JP, et al. Advanced maternal age and pregnancy outcomes: a multicountry assessment. Br J Obstet Gynaecol 2014;121(1):49-57.
37. Wu TP, Liang FW, Huang YL, Chen LH, Lu TH. Maternal mortality in Taiwan: a nationwide data linkage study. PLoS One 2015;10(8):1-11.

38. Lee QY, Odoi AT, Opare-Addo H, Dassah ET. Maternal mortality in Ghana: a hospital-based review. Acta Obstet Gynecol Scand 2012;91(1):87-92.

39. Nove A, Matthews Z, Neal S, Camacho AV. Maternal mortality in adolescents compared with women of other ages: evidence from 144 countries. Lancet Glob Heal 2014;2(3):155-64.

40. Xiaoli L, Weiyuan Z. Effect of maternal age on pregnancy: a retrospective cohort study. Chin Med J (Engl) 2014;127(12): 2241-6.

41. Temmerman M, Verstraelen H, Martens G, Bekaert A. Delayed childbearing and maternal mortality. Eur J Obstet Gynecol Reprod Biol 2004;114(1):19-22.

42. Gupta SD, Khanna A, Gupta R, Sharma NK, Sharma ND. Maternal mortality ratio and predictors of maternal deaths in selected desert districts in Rajasthan: a community-based survey and case control study. Womens Health Issues 2010;20(1):80-5.

43. Neilson JP, Lavender T, Quenby S, Wray S. Obstructed labour: reducing maternal death and disability during pregnancy. $\mathrm{Br}$ Med Bull 2003;67(1):191-204.

44. Ganatra B, Faundes A. Role of birth spacing, family planning services, safe abortion services and post-abortion care in reducing maternal mortality. Best Pract Res Clin Obstet Gynaecol 2016;36:145-55.

45. Carolan MC, Davey M-A, Biro M, Kealy M. Very advanced maternal age and morbidity in Victoria, Australia: a population based study. BMC Pregnancy Childbirth 2013;13(80):1-8.

46. Ludford I, Scheil W, Tucker G, Grivell R. Pregnancy outcomes for nulliparous women of advanced maternal age in South Australia, 1998-2008. Aust New Zeal J Obstet Gynaecol 2012;52(3):235-41.

47. Hsieh T-T, Liou J-D, Hsu J-J, Lo L-M, Chen S-F, Hung T-H. Advanced maternal age and adverse perinatal outcomes in an Asian population. Eur J Obstet Gynecol Reprod Biol 2010;148(1):21-6.

48. Bayrampour $\mathrm{H}$, Heaman M. Advanced maternal age and the risk of cesarean birth: a systematic review. Birth (Berkeley, Calif.) 2010;37(3):219-26.

49. Chan BCP, Lao TTH. Effect of parity and advanced maternal age on obstetric outcome. Int J Gynecol Obstet 2008;102(3):237-41.

50. Callaway LK, Lust K, McIntyre HD. Pregnancy outcomes in women of very advanced maternal age. Aust N Z J Obstet Gynaecol 2005;45(1):12-6.

51. Arps S. Threats to safe motherhood in Honduran Miskito communities: Local perceptions of factors that contribute to maternal mortality. Soc Sci Med 2009;69(4):579-86.

52. Cheng JJ, Schuster-wallace CJ, Watt S, Newbold BK, Mente A. An ecological quantification of the relationships between water, sanitation and infant, child, and maternal mortality. Environ Heal 2012;11(4):1-8.

53. Taguchi N, Kawabata M, Maekawa M, Maruo T, Dewata L. Influence of socio-economic background and antenatal care programmes on maternal mortality in Surabaya, Indonesia. Trop Med Int Heal 2003;8(9):847-52.

54. Mason KO. The status of women: conceptual and methodological issues in demographic studies. Sociol Forum 1986;1(2):284-300.

55. Dyson T, Moore M. On kinship structure, female autonomy, and demographic behavior in India. Popul Dev Rev 1983;9(1):35-60. 
56. Balk D. Individual and community aspects of women's status and fertility in Rural Bangladesh. Popul Stud (NY) 1994;48(1):21-45.

57. Morgan SP, Niraula B. Gender inequality and fertility in two Nepali villages. Popul Dev Rev 1995;21(3):541-61.

58. Woldemicael G. Women's status and reproductive preferences in Eritrea. Germany; 2007. Report No.: 23. Available from: http:// www.demogr.mpg.de.

59. Hou X, Rashid M, Vermehren A, Khan AZ, Mete C, Friedman J, et al. Empowering women through BISP: The effect of women's decision making Power on reproductive health services uptake in Pakistan. Pakistan; 2011. Report No.: 64407. Available from: http://documents.worldbank.org/curated/
en/645611468098990648/pdf/644070WP0SPOPo00Reproduct ive0Health.pdf.

60. Chatterjee A, Paily VP. Achieving millennium development goals 4 and 5 in India. Br J Obstet Gynaecol. 2011;118(SUPPL. 2):47-59.

61. Pritchett L, Summers LH. Wealthier is healthier. J Hum Resour 1996;31(4):841-68.

62. Essendi H, Johnson FA, Madise N, Matthews Z, Falkingham J, Bahaj AS, et al. Infrastructural challenges to better health in maternity facilities in rural Kenya: community and healthworker perceptions. Reprod Health 2015;12(103):1-11.

63. Nour NM. An introduction to maternal mortality. Rev Obstet Gynecol 2008;1(2):77-81. 